Isabel Niemöller

Das Kadiamtsprotokollbuch von Mardin 247 


\section{Islamkundliche Untersuchungen}

Band 341 
Isabel Niemöller

\section{Das Kadiamtsprotokollbuch von Mardin 247}

Edition, Übersetzung und kritischer Kommentar 
Dieses Buch ist die überarbeitete Fassung der an der Ludwig-Maximilians-Universität München angenommenen Dissertation der Autorin.

Die Faksimiles zum Text sind als Supplement Material auf der Internetseite abrufbar: https://www.degruyter.com/view/title/569534

ISBN 978-3-11-067509-2

e-ISBN (PDF) 978-3-11-067514-6

e-ISBN (EPUB) 978-3-11-067520-7

Library of Congress Control Number: 2020940950

Bibliografische Information der Deutschen Nationalbibliothek

Die Deutsche Nationalbibliothek verzeichnet diese Publikation in der Deutschen Nationalbibliografie; detaillierte bibliografische Daten sind im Internet über http://dnb.dnb.de abrufbar.

(C) 2020 Walter de Gruyter GmbH, Berlin/Boston

Umschlagabbildung: Ausschnitt aus Blatt 13 des Kadiamtsprotokollbuchs 247 von Mardin Druck und Bindung: $\mathrm{CPI}$ books $\mathrm{GmbH}$, Leck

www.degruyter.com 
meinem Vater

Heinz Hermann Niemöller 
